\title{
REVISIÓN
}

\section{EUROPA Y EL MUNDO ATLÁNTICO. RESEÑA HISTORIOGRÁFICA}

\author{
Marcello Carmagnani \\ El Colegio de México
}

Dara entender la importancia y el significado de la parti-
cipación de Europa en la construcción del mundo atlántico es necesario hacer algunas consideraciones respecto a la novedad de la presencia del océano Atlántico en la sociedad moderna, la diferenciación existente entre Europa y las zonas atlánticas extraeuropeas, y la fuerza relativa de las potencias europeas para instalarse en zonas atlánticas en las que los factores naturales, sociales y culturales diferían mucho de los existentes en Europa.

El océano Atlántico se extiende entre Europa y África al oriente y la América septentrional y meridional al occidente. Es el segundo océano de la Tierra, cuya superficie recubre $20 \%$, y su volumen es de $82300000 \mathrm{~km}^{2}$. Este volumen de agua consiste en cuatro masas marinas principales que en el Atlántico Norte circulan en el sentido horario mientras en el Atlántico Sur lo hacen en sentido contrario con mareas que se mueven de sur a norte y que todavía en el transcurso del siglo xvi dificultaban la navegación entre Europa y América. 
El dominio del océano requería no sólo del desarrollo de técnicas nuevas de navegación y de construcción de naves capaces de surcar las nuevas rutas marítimas, sino también un fortalecimiento del capital mercantil para hacer frente a los nuevos retos. No sorprende constatar que las potencias europeas hayan confiado este cometido a nobles y a comerciantes quienes, por cuenta propia, exploraron, conquistaron y ocuparon con patentes reales las zonas atlánticas de África y América. La debilidad del capital mercantil y los reducidos recursos financieros de las monarquías europeas obligaron a los conquistadores a inventar, basándose en sus conocimientos, cómo relacionarse con culturas diferentes a las suyas, las cuales tenían organizaciones estatales o tribales complejas y formas de conflicto similares a las europeas.

Los conquistadores se dieron cuenta tardíamente de que tenían que superar el sistema productivo existente en África y América y crear formas de asentamiento permanentes que permitieran que las sociedades no europeas entendieran la importancia de utilizar la fuerza animal y las técnicas que ellos estaban introduciendo para hacer frente a la drástica reducción de la población amerindia y africana provocada por la presencia europea. Con estas premisas, en el siglo XvI los colonizadores iniciaron la convergencia progresiva entre las zonas atlánticas de Europa, África y América.

Este estudio, producto de una relectura de la bibliografía que se menciona al final del texto, tiene como objetivo principal volver a pensar la diacronía de los cambios que acontecieron en el mundo atlántico entre 1500 y 1830.

En la primera parte ilustro las premisas del encuentro atlántico, cuyo punto de partida es el descubrimiento de América en 1492 y la llegada a la India de Vasco de Gama en 1498. 
El argumento de la segunda parte concierne a las dificultades que enfrenta el nacimiento del mundo atlántico durante siglo y medio, desde el xvi hasta la primera mitad del xvir.

En la tercera parte del estudio presento la forma que asume en el transcurso del siglo xvir el intercambio trilateral entre Europa, África y América, la nueva forma de producción colonial, el papel desempeñado por las fusiones étnicas y, por último, los diversos grados de control de las zonas atlánticas extraeuropeas por parte de las metrópolis.

La consolidación del mundo atlántico en el sistema colonial del antiguo régimen sucede entre fines del siglo xvir y el Xviri. Esto fue posible por la revolución comercial que desarrolló los nuevos consumos europeos gracias a la reducción de los precios de los productos exóticos americanos y asiáticos. En esta fase histórica es cuando las zonas americanas comienzan a diferenciarse de las europeas y a oponerse al fortalecimiento de las políticas coloniales de las metrópolis europeas.

En la última parte del estudio analizo las dimensiones que tienen en común las revoluciones atlánticas, que tanto en Europa como en América acaecieron entre 1776 y 1830.

Mi interés concierne tanto a la redefinición de la diacronía de las transformaciones del mundo atlántico como a poner de relieve las dimensiones que comparten las diversas experiencias de las zonas atlánticas, algo que las hace partícipes de la historia mundial.

EL ENCUENTRO DE EUROPA CON ÁFRICA Y AMÉRICA

Para entender cómo el Atlántico hace posible el encuentro de Europa con África y las Américas es necesario abandonar la 
visión de la vieja historia de la expansión europea que ve una avanzada progresiva de Europa a partir del siglo XIII.

La creación del mundo atlántico requería la superación definitiva del modelo europeo de explotaciones mercantiles medievales y el nacimiento de un nuevo modelo de colonización con asentamientos permanentes. El pretendido avance de los conquistadores a lo largo de las islas y la costa atlántica no es, por ende, la fase preparatoria del nacimiento del mundo atlántico sino, antes bien, la búsqueda por parte de las monarquías de conectar los diversos mares europeos.

La conexión entre estos mares es una fuente de ganancias y un espacio de poder para las monarquías europeas. Los gobiernos, deseosos de extender su prestigio y sus propios recursos financieros, amplían el campo de acción, pero terminan por expandir los antagonismos y conflictos preexistentes. Comerciantes y propietarios de naves se dan cuenta de que el avance marítimo y el perfeccionamiento de las técnicas de navegación han aumentado tanto el giro de sus negocios como las ganancias. La toma de posesión del mar más cercano tiene motivaciones muy distintas, como la avanzada del Islam, que impide que se siga abasteciendo de oro a Europa por las rutas saharianas; el auge progresivo de Amberes, Ámsterdam y Londres; la regresión de Génova y Venecia y las ciudades mediterráneas españolas y francesas; y finalmente, la proyección hacia África de Lisboa y Sevilla, resultado de la configuración de las costas europeas.

No hay que olvidar que los puertos atlánticos europeos estaban en condiciones de innovar la tradición mediterránea, conservando no obstante, con este mar, relaciones económicas y financieras, como lo ilustra la presencia en las plazas de Sevilla, Lisboa, Amberes, Ámsterdam y Londres de hombres 
de negocios del Mediterráneo. La toma de posesión del mar más cercano reforzó inicialmente las zonas de los mares del Norte y Báltico, y fue posible gracias a sus propios recursos técnicos y sociales. La vertiente atlántica de Europa poseía abundantes materias primas que eran necesarias para la adaptación de las técnicas de navegación. El tránsito de la carabela a los grandes veleros, galeones, fragatas y otros tipos de navíos fue posible gracias a los recursos locales de madera para los cascos, del abasto de pez y brea, de hierro para las anclas españolas y suecas, y de telas para las velas y de cordaje provenientes de Bretaña. Las costas europeas de la vertiente atlántica ofrecían la posibilidad de reclutar tripulación con una capacidad enriquecida por la experiencia. Para los viajes a los mares del Norte era necesario confiar en experimentados pilotos portugueses, españoles, flamencos, ingleses e italianos. El reclutamiento de la tripulación se hacía localmente con pescadores o marineros de cabotaje, mano de obra accesible en las costas inglesas, bretonas, portuguesas y españolas.

La empresa que mejor expresa la primera proyección atlántica de Europa es la búsqueda por los ingleses de bancos de pesca. Después de haber sido rechazados del mercado pesquero de Bergen (Noruega) por los hanseáticos y de haber sondeado en aguas islandesas, los ingleses se dirigen hacia el oeste, donde encuentran Terranova, en la segunda mitad del siglo xv. Los bancos de pesca de Terranova no tardan en aparecer en las cartas náuticas como una prolongación de las zonas de pesca europeas. La experiencia inglesa estimuló la navegación a Terranova de los normandos y de los pescadores de Nantes, La Rochelle y Burdeos, pero también la de los vizcaínos y portugueses, que dieron el nombre al lugar. 
Sin embargo, la presencia genovesa en Marruecos y en las islas atlánticas de las Azores y las Canarias no se puede considerar una avanzada en el Atlántico. Lo mismo que en el Mediterráneo, los genoveses están interesados en el comercio del trigo y del vino de Marruecos y de las islas, y participan con los españoles y los portugueses en el cultivo de caña de azúcar y en el comercio del azúcar de las islas atlánticas. En Canarias, los genoveses participan en la producción del azúcar que utiliza la población local, los guanches, reducidos a la servidumbre y exterminados progresivamente, como sucederá más tarde con los amerindios del Caribe. La expansión por la costa atlántica africana es contemporánea a la llegada de los ingleses a Terranova; sucede también en el siglo xv, gracias a la adecuación de la técnica de las naves hanseáticas a la navegación de las costas africanas. Los portugueses, una vez alcanzado el cabo Bojador en 1434 y hasta su llegada al de Buena Esperanza en 1487, establecieron 14 factorías comerciales que lograron interceptar el oro de Mali, del Alto Níger y el Alto Volta, y reforzar la trata de esclavos.

$\mathrm{Al}$ inicio, todo el nuevo comercio portugués le fue concedido a la compañía mercantil de Fernando Gomes, de Lisboa, pero desde 1481 se volvió monopolio de la corona, que incentivó el comercio de las explotaciones agrícolas africanas. Se intercambia oro y esclavos por caballos, textiles, cobre, zinc, bronce, brazaletes y camas de madera. Se calcula que los portugueses transportaron 150000 esclavos que fueron vendidos en Europa entre 1400 y 1500 . A pesar de la multiplicidad de experiencias europeas que se difundieron y se fueron adoptando en las diversas zonas portuarias de la vertiente atlántica en el transcurso del siglo xv, fueron los portugueses los primeros en proyectarse hacia África sin 
convertirse por ello en los primeros actores del mundo atlántico. Este mérito corresponde a la empresa financiada por Castilla y guiada por Cristóbal Colón, quien en 1492, atravesando el océano, llega al Caribe. Con Vasco de Gama, quien en 1498 desembarca en Calcuta, India, son los portugueses los que se arriesgan a demostrar que el Atlántico es un océano que se conecta con el océano Índico y el Mar de China por el este, y por el oeste permite llegar al Nuevo Mundo.

\section{EL NACIMIENTO DEL MUNDO ATLÁNTICO}

El mundo atlántico nace en el siglo xvi. Su punto de partida es el encuentro-desencuentro que tiene lugar entre las potencias europeas y las luchas internas de los amerindios y de los reinos africanos, las que definieron las primeras relaciones entre los invasores europeos y las poblaciones no europeas e hicieron posibles las primeras formas de colaboración en el mundo atlántico. Los principales vectores de la redefinición de las interacciones entre los grupos europeos y amerindios en el mundo atlántico es sin duda la catástrofe demográfica de la población americana y el inicio de la exportación de esclavos africanos. Los europeos son portadores de epidemias desconocidas entre los amerindios, con el resultado de que en menos de un siglo, la viruela, el tifus, el sarampión, la influenza, la neumonía y otras epidemias redujeron enormemente el número de amerindios en las diversas regiones americanas. La consecuencia del desplome demográfico amerindio es la gran deportación de esclavos africanos hacia las regiones americanas. La catástrofe demográfica americana y la esclavitud africana se acentuaron también seguramente con las formas de violencia introducidas por los europeos en 
los dos continentes. En el transcurso del siglo Xvi el comercio de esclavos registró un aumento notable, de 900 a 2100 esclavos anuales en el periodo de 1501 a 1525, hasta llegar a los 5600 esclavos anuales en el periodo de 1576 a 1600. Inicialmente, la mayor parte de los africanos fueron absorbidos en el área atlántica iberoamericana.

Los efectos del despoblamiento americano y africano fueron enormes. En el transcurso del siglo Xvi, impidió el establecimiento permanente de franceses, ingleses y holandeses tanto en América como en África, y éstos se vieron constreñidos a adquirir las riquezas africanas y americanas por medio de trueque con las poblaciones locales, del saqueo de los asentamientos españoles y de la captura de naves enemigas. En la región iberoamericana el paso de la explotación agrícola comercial al asentamiento fue muy lento en las zonas españolas, mientras que las portuguesas se mantuvieron en la fase de las explotaciones agrícolas comerciales. Se puede entender así por qué todos los europeos, incluidos los españoles, continuaron intercambiando los productos amerindios por los europeos, valiéndose de formas impuestas de intercambio. En África, las explotaciones agrícolas portuguesas y las primeras de los demás países europeos incrementaron el intercambio de esclavos y oro por productos europeos textiles de algodón provenientes de la India. La imposibilidad de un asentamiento colonial europeo rápido en las regiones americanas y africanas estuvó condicionada además por la escasa inmigración europea. En el curso del siglo xvi transmigraron apenas 430 europeos al año.

Los holandeses, entre todos los europeos, fueron los primeros en obtener ventajas en el curso de la precaria fase de inicio del mundo atlántico. Gracias a su capacidad de inter- 
mediación, adquirieron un papel preponderante en la reexportación de los productos africanos y americanos a las zonas del Mediterráneo, de Europa del norte y oriental y del Báltico. La capacidad de movimiento de las naves holandesas en el Atlántico explica también la inmigración inicial de judíos y esclavos en América del Norte. Los holandeses se aprovecharon también de su presencia en las Canarias, que se habían convertido en el puerto central de las naves en dirección a Iberoamérica para el contrabando, por medio del tráfico español que se dirigía hacia el Nuevo Mundo, de productos europeos comerciales en el mundo americano. Con la oferta de créditos y reducidas tarifas de flete marítimo, las explotaciones agrícolas comerciales holandesas del Caribe lograron crear un lucrativo comercio con las islas inglesas de Barbados, San Cristóbal y, en el continente, con Virginia.

Todavía a principios del siglo Xvir, los países europeos del Atlántico Norte no estaban en condiciones de desafiar las posiciones que los ibéricos habían adquirido en el mundo atlántico americano. Esto no significa que el saqueo de las naves ibéricas, los desembarcos en varios puertos y el contrabando no fueran lucrativos, pese a que el monopolio comercial ibérico y el poder marítimo y territorial español permanecieran prácticamente intactos. De la información de que se dispone se deduce hasta qué punto es inexacta la imagen de que los españoles y los portugueses fueron los únicos europeos en haber creado un sistema capaz de dar continuidad a la comunicación y al comercio en el Atlántico del siglo xvi. Hay que decir, en cambio, que en el siglo xvi España tiene una presencia notable en las rutas marítimas y terrestres que conectaban las capitales coloniales con los puertos, mientras que su presencia es menor en el interior de los 
territorios. Los obstáculos al asentamiento ibérico derivan del despoblamiento, que fue casi total en la zona del Caribe, y de la imposibilidad de impedir la filtración de holandeses, franceses e ingleses en el continente americano. La fuerza de los españoles deriva de la estrategia utilizada por las empresas de la conquista en las zonas continentales.

Partiendo de la isla de Cuba, Hernán Cortés, encabezando una expedición de pocos hombres, llega a las costas de México e invade el imperio de la Triple Alianza (formada por las principales ciudades: Tenochtitlan de los mexicas, Texcoco de los acolhua-chichimecas, y Tlacopan de los tepanecas). De Panamá partieron los capitanes a la conquista del Perú y de Chile. Panamá es también el puesto de avanzada en dirección a Venezuela y Colombia. Todas las expediciones españolas de la primera mitad del siglo xvi emplearon un número muy limitado de conquistadores, no más de 2000, y de ahí que la gran originalidad de la conquista española sea la capacidad de establecer alianzas con los señores amerindios, como sucedió en las conquistas de las civilizaciones estatales de México y Perú y en las de la civilización tribal de otras regiones americanas. Así, sin la alianza entre españoles y amerindios, la corona española no hubiera sido capaz de establecerse en América. Esta estrategia fundada en la alianza es lo que puede explicar la política de la corona española, dispuesta a impedir los abusos de los conquistadores y de sus descendientes para obtener la colaboración entre autoridades españolas y señores amerindios. Con la cooperación de las clases dirigentes amerindias, los españoles consiguen controlar las áreas estratégicas americanas a partir de 1570.

También la corona portuguesa, con la ayuda y las alianzas con las civilizaciones tribales, logra ocupar las regiones bra- 
sileñas y liquidar los asentamientos franceses. A diferencia de España, el asentamiento portugués tiene lugar mediante donación real, en 1533, de 12 territorios (capitanías) a nobles portugueses. No obstante la creación de un gobierno general para Brasil en 1549, con sede en Bahía, la corona sólo logra ejercer un control muy limitado sobre las capitanías privadas. La dominación ibérica de los territorios americanos se refuerza a partir del control de las rutas atlánticas con la creación de los monopolios reales del comercio, la Casa de Contratación española y la Casa da Mina (Casa de Indias) portuguesa. Sin embargo, sólo en el transcurso de la segunda mitad del siglo xvi se volverá permanente la conexión marítima entre las metrópolis y las colonias. El establecimiento en los territorios atlánticos ibéricos se ve potenciado por la difusión del catolicismo a cargo de franciscanos, dominicos y agustinos. Con el concurso de los clérigos, la población amerindia es cristianizada y con la ayuda de los conventos adquiere el uso de la nueva energía animal, del arado y de las técnicas agrícolas europeas, con las que logra disminuir los problemas derivados de la falta de población, que en las zonas amerindias era particularmente relevante.

El fortalecimiento de la colonización española depende también de la presencia de los funcionarios reales, del virrey en México y en Perú, y de los gobernadores en las otras colonias, mientras que los funcionarios señoriales en Brasil no tenían gran capacidad de control de sus territorios. La presencia de los funcionarios reales españoles y de los funcionarios señoriales portugueses se vio limitada con el nacimiento de los municipios, que organizan a la población española y amerindia en las regiones españolas, y de las cámaras municipales en las regiones luso brasileñas. Con los municipios, 
dominados por notables coloniales ibéricos, se refuerza el control territorial, permitiendo la sucesiva difusión de la administración colonial que garantizará la participación de Iberoamérica en las monarquías española y portuguesa.

A diferencia de la nueva realidad en la América ibérica, el avance portugués en África fue escaso; allí siguió persistiendo el sistema preexistente de las factorías comerciales con escasa penetración tierra adentro.

\section{EL MUNDO ATLÁNTICO EN LA HISTORIA MUNDIAL}

La integración del mundo atlántico en la historia mundial sucede en el periodo que abarca la superación de la crisis general del siglo XVII y los últimos decenios de ese mismo siglo.

Con el fin del colapso demográfico amerindio y el fomento de las importaciones de esclavos africanos se expande la nueva población mestiza y mulata y se multiplican las generaciones de europeos nacidos en América. El mundo atlántico ibérico, a diferencia del inglés y el francés, posee la capacidad de integrar las culturas europeas, amerindias y africanas, dando origen a las civilizaciones mestizas latinoamericanas. Los indicadores económicos más significativos del mundo atlántico son el crecimiento de la producción de plata, iniciada en las últimas décadas del siglo xvi, y la primera conformación de la agricultura comercial exportable a Europa. La plata de la América española y el azúcar de la América portuguesa son en realidad las primeras señales de la participación de América en la nueva economía atlántica y mundial. La producción de plata alcanza su máxima expansión en la primera mitad del siglo xviI y continuará incrementándose más lentamente en la segunda mitad del siglo. 
Entre 1600 y 1650, la producción de plata es de $368 \mathrm{~kg}$ anuales, de los que 268 (78.8\%) se van a Europa. De los $268 \mathrm{~kg}$ anuales que llegan a Europa, 56 parten en dirección al Báltico, 38 acaban en el Mediterráneo y 15.5 emprenden el camino a Asia. Este continente recibe también de América, vía las Filipinas, en poder de España, $100 \mathrm{~kg}$ anuales del metal, equivalentes a $27.2 \%$ de la producción americana.

La circulación de la plata americana favoreció sin lugar a dudas la monetización de las economías americanas y fomentó la de la europea, así como los intercambios comerciales con Asia y entre América y Asia. El capital mercantil se amplió y las finanzas de las monarquías europeas se reforzaron con el incremento del comercio exterior. El Atlántico portugués también contribuye de manera importante al crecimiento europeo con su azúcar, producido en las regiones del noreste de Pernambuco y Bahía. En el transcurso del primer tercio del siglo xvir, la producción de azúcar aumentó rápidamente, de 27000 a 46000 toneladas, hasta alcanzar las 100000 a mitad del siglo. Esta expansión productiva depende especialmente de la introducción de nuevas técnicas durante la ocupación holandesa de las regiones azucareras (1624-1654).

$\mathrm{Al}$ azúcar brasileño es necesario añadir el que comienza a producirse en las plantaciones de las islas inglesas, francesas y holandesas de las Antillas, que duplicará la llegada a Europa de la melaza ya en la década de 1650-1659.

De importancia similar es el inicio de la producción para el comercio de una planta americana, el tabaco, de Virginia y de Brasil, hacia la mitad del siglo xvir. Se trata de dos calidades de tabaco que satisfacen el gusto europeo: el tabaco rubio de Virginia y el negro de Brasil. Cerca de 10 toneladas 
de ambos tabacos llegan anualmente a Inglaterra y Portugal para a ser exportados a toda Europa a mitad del siglo xviI.

Las nuevas producciones de plata y de productos exóticos explican la capacidad del mundo atlántico para superar los obstáculos del siglo precedente. Estos obstáculos se vencieron gracias a la oferta casi ilimitada de recursos naturales - tierra y minería - a la adaptación de las técnicas europeas y a las innovaciones introducidas por los americanos y, en definitiva, superando la falta de mano de obra con la importación de esclavos africanos y convirtiendo las nuevas poblaciones americanas de mestizos y mulatos en mano de obra servil. El Nuevo Mundo es testigo del nacimiento de una nueva realidad productiva agrícola, las plantaciones. La plantación azucarera americana es una nueva forma productiva que integra la abundante oferta de tierra con la reducida disponibilidad de mano de obra y con las innovaciones técnicas introducidas por holandeses e ingleses en Brasil y en el Caribe. Esta forma de producción se expande también en la América continental ibérica, francesa e inglesa. En las plantaciones de la América atlántica se logra incrementar la cantidad de melaza producida que después se convertirá en azúcar en las refinerías europeas antes inexistentes. Las plantaciones, como hemos dicho, solucionan la escasez de mano de obra con la importación de esclavos que, además de permitir la producción de bienes de exportación, aseguran a las plantaciones las materias primas necesarias para la producción de azúcar: madera, bienes para el sustento de la mano de obra esclava y no esclava, y el ganado necesario para la producción y el transporte del producto.

Antes de la era de las plantaciones, se supera en América el sistema tradicional de producción europeo de la plata, como 
el practicado en Alemania con la fusión del mineral para obtener el metal precioso. En América nace el sistema de la amalgama, que mediante la mezcla del mineral de argento con mercurio permite la separación del metal, sin el uso de fuego, de las otras sustancias minerales. Mediante la amalgama se puede obtener el metal preciado, también con mineral de menor contenido argénteo, a un costo inferior. Los latifundios asociados a los centros minerales ofrecen la madera a un precio reducido, la energía animal y los bienes de consumo para el sustento de los trabajadores, a los que se retribuye con un salario pagado en especie.

Inicialmente la trata de esclavos en todas las plantaciones atlánticas americanas estuvo en manos de los portugueses, y más tarde también es practicada por comerciantes holandeses, franceses e ingleses. A la trata se suma la primera oleada de inmigrantes en dirección al Atlántico británico de trabajadores endeudados, indentured servants, que vendían su propio trabajo a cambio del precio del transporte marítimo. También en este caso se trata de trabajo servil, no diferente sustancialmente al que se daba en la América ibérica.

Entre 1580 y 1640, la trata de esclavos traslada cada año una media de 12600 individuos que se convierten en 30000 , también al año, entre 1650 y 1700, de África a América. En ese mismo periodo, la inmigración europea, principalmente británica y alemana, que llega al Caribe y al área continental británica, es de 2400 personas al año. La conjunción de mano de obra esclava africana y la de siervos americana y europea favorece por ende la integración del mundo atlántico africano, americano y europeo. Probablemente el trabajo forzoso desciende de la organización de la sociedad estamental del mundo atlántico. No obstante, en América 
esta organización no tiene la fuerza jerárquica que presenta en las metrópolis, dada la presencia de una pluralidad étnica y el hecho de ser un territorio poco controlado administrativamente por las metrópolis. La sociedad estamental americana expresa, no obstante, los mismos principios europeos del honor, el prestigio y la riqueza. El orden estamental americano evitó a las metrópolis la organización de un ejército, puesto que en las colonias ibéricas, francesas e inglesas la responsabilidad de la defensa del territorio se confiaba a las organizaciones municipales, a la asamblea de los colonos y a los propietarios de los latifundios.

Otros instrumentos capaces de favorecer la relación entre las metrópolis y las colonias atlánticas son la fe católica, para el Atlántico ibérico y para el francés naciente, y la fe anglicana, presbiteriana y protestante radical en el Atlántico británico. De este modo se puede explicar la importancia que tuvo la "conquista espiritual" en todo el mundo atlántico americano, lo mismo que su ausencia en África.

Sin la cristianización de los amerindios, de los esclavos y de las poblaciones americanas derivadas de la fusión étnica, la misma organización estamental no se hubiera consolidado. Podemos comprender así la importancia del sostén ofrecido por la corona ibérica a la conquista espiritual, que obtuvo del papado, a título de reciprocidad, la asignación del patronato religioso en América.

A diferencia de las zonas ibéricas, la corona inglesa no apoyó a la iglesia de Inglaterra en todas las colonias americanas. Lo hizo sólo en las colonias del Caribe, Nueva York, New Jersey, Virginia y en las colonias al sur de Pensilvania. Esto favoreció, con el apoyo de los colonos, la difusión de las otras religiones protestantes en las colonias continentales inglesas. 
No obstante, huelga decir que el celo de las coronas y de las jerarquías, de los misioneros y del clero, no logra impedir el surgimiento de una pluralidad de formas religiosas sincréticas, todavía presentes en el mundo atlántico americano.

A esta dimensión religiosa capaz de ofrecer un apoyo importante a la reordenación que tratan de introducir las metrópolis europeas en América, se agrega la organización de la actividad marítima y comercial. La flota española, a la que se ha confiado el tráfico entre España y América, es un monopolio real organizado por la Casa de Contratación a favor de los comerciantes de Sevilla, que consiguen armar una flota con dos terminales americanas, Veracruz en México y Nombre de Dios en Panamá, y un puerto central en La Habana, Cuba. El monopolio funciona gracias a la colaboración, en las sedes virreinales de la ciudad de México y de Lima, del Tribunal del Consulado. Las dos corporaciones mercantiles organizan a los comerciantes hispanoamericanos más importantes, encargados de gestionar, junto con los funcionarios reales de la flota y los mercaderes de Sevilla, el intercambio entre las mercancías americanas y las europeas. Los portugueses, aunque conservando el monopolio real del comercio tanto en África como en América, lo confían en Brasil a las compañías mercantiles portuguesas que operan con frecuencia con naves extranjeras autorizadas por la corona.

En el Atlántico británico, la organización del tráfico mercantil se dejó en manos de compañías privadas, autorizadas con licencia real, que operaban tanto en el continente como en el Caribe y en África occidental. Las principales compañías obtienen la licencia real subordinada a la condición de 
promover la creación de asentamientos en Virginia, Massachusetts y Providence.

En las zonas portuguesas donde inicialmente regía el sistema de la capitanía, la corona fue transformando progresivamente esta institución en gubernaturas con un poder judicial real. Las cámaras municipales que ejercen el control de la dimensión local pasan a manos de magnates luso brasileños. En la América española se refuerza el poder de la administración real en los virreinatos y en las gubernaturas, y crece el poder de la Audiencia, tribunal de justicia y de asistencia política al virrey y los gobernadores. La recaudación de los gravámenes internos de las colonias se subcontrata a los nobles hispanoamericanos, mientras que el control de los impuestos al comercio de importación y de exportación sigue siendo responsabilidad del fisco real. Por ende, los municipios españoles y amerindios aumentan su propia importancia en el ámbito local.

En el mundo atlántico inglés, el autogobierno es el principio fundamental de la organización político administrativa. El autogobierno se regula en cada colonia por la asamblea de los colonos. A este organismo la corona le concede el privilegio de definir las leyes que los mismos colonos consideren más convenientes. En consecuencia, cada una de las colonias desarrolla una constitución propia, pero en todas ellas es la asamblea de los colonos la que posee el poder concreto, aunque dentro del marco que las confirma como dominios inferiores subordinados al poder superior que corresponde a la corona. La organización de las colonias inglesas reelabora el orden social basado en la diferencia y la desigualdad de los estratos sociales. Esto hace que, como en la América ibérica, también en las colonias inglesas haya una gran diferen- 
ciación en la población por la diversidad existente entre las élites locales y los estratos sociales inferiores.

\section{LA CONSOLIDACIÓN DEL MUNDO ATLÁNTICO}

La consolidación del mundo atlántico tiene lugar entre las últimas décadas del siglo Xvir y el último tercio del XviII. En el curso de este arco temporal todos los vectores económicos, sociales y políticos presentes alrededor de 1650 sufren una rápida aceleración que favorece el acercamiento de las zonas atlánticas a las dimensiones europeas, si bien manteniendo cada región alguna especificidad propia, pero comenzando a manifestarse en el mundo americano una resistencia creciente a las políticas coloniales de las metrópolis.

El adelanto del mundo atlántico respecto a Asia es el principal acontecimiento del periodo que, como se dirá en la última parte de este ensayo, tendrá consecuencias relevantes de naturaleza política en América y Europa.

Es bien sabido que en el siglo Xvir Asia es el continente que más interesa a los países atlánticos europeos. Europa tiene también con Asia una balanza de pagos deficitaria por el desinterés declarado de las zonas asiáticas por las mercancías europeas.

Gracias a la plata proveniente de América, la Europa atlántica logra equiparar la adquisición de tejidos indios y chinos, azúcar, té, café y cerámicas valiosas. El equilibrio comercial entre Europa y Asia favorece sin duda el crecimiento del tráfico de nuevos productos provenientes de las colonias americanas.

En competencia con los productos asiáticos que interesan a Europa, las zonas atlánticas tienen la ventaja de contar con mano de obra esclava y de haber creado en la vertiente 
americana un sistema productivo gobernado directamente por cultivadores de origen europeo. En el mundo asiático, la organización de la producción de los bienes exportados depende del vínculo entre productores locales y agentes de las compañías privilegiadas europeas, con el resultado de que las compañías privilegiadas nunca lograron penetrar con eficacia en los sistemas productivos asiáticos. La formación de compañías privilegiadas en el Atlántico americano se ve obstaculizada en cambio por los grandes productores euroamericanos.

Conviene tener presente que el sistema productivo americano es una forma organizativa fundada en la autosuficiencia de las plantaciones y de los centros mineros, los dos polos que elaboran los bienes necesarios para la producción comercializada y para el sustento de la mano de obra. El sistema productivo americano logra colmar la falta de mano de obra con la trata de esclavos y con el incremento de la población mestiza y mulata. La llegada de los esclavos a América crece de 18600 a 30900 individuos anuales entre 1651 y 1700, y entre 1700 y 1800 se duplica, alcanzando el pico de 68329 en un año. Si agregamos la inmigración europea en la América inglesa, que incrementa la población de 69800 a 230000 individuos entre 1650 y 1800, y la población mestiza y mulata en la América ibérica, que aumenta de 2300000 a 15000000 en el mismo periodo, se puede pensar que el incremento demográfico influyó positivamente en el crecimiento de las producciones y exportaciones en la América atlántica.

En síntesis, el esfuerzo productivo capaz de hacer más competitivos los bienes americanos se debe a la circunstancia de que el Atlántico americano superó definitivamente el obstáculo demográfico e introducido numerosas actualiza- 
ciones técnicas productivas y en el transporte marítimo que impedían su inserción plena en la economía internacional y, por ende, llegó a producir una creciente cantidad de bienes exportables a un costo inferior al asiático.

El resultado de la competencia entre los productos atlánticos y asiáticos se puede observar en el crecimiento de las exportaciones. El azúcar asiático, proveniente de Java, es exportado en cantidad de 1000 toneladas anuales entre 1651 y 1670, después de lo cual desaparece del mercado europeo. En cambio, el azúcar exportado de América aumenta de 100 a 50000 toneladas anuales entre 1670 y 1780 . El café exportado de Asía no llega a superar las 1000 toneladas anuales entre 1701 y 1800 , mientras que el americano pasa a de 10000 a 50000 toneladas anuales en el periodo de 1701 a 1800. El tabaco americano, a pesar de la producción europea, aumenta de 8000 a 40000 toneladas anuales en el periodo de 1670 a 1780. Al avance americano en el comercio de productos exóticos se agrega la expansión de las exportaciones de metales preciosos producidos en la América ibérica. A la producción de plata de México y Perú, se suman la plata y el oro de Chile, y el oro de Brasil y de Colombia, sin contar los diamantes brasileños. La producción total de metales preciosos se puede estimar en $2000 \mathrm{~kg}$ de plata anuales en el periodo de 1650 a 1780 , de los que $90 \%-1800 \mathrm{~kg}$ anuales - emprenden la ruta a Europa, de donde solamente $200 \mathrm{~kg}$ anuales son enviados a Asia. De los $1600 \mathrm{~kg}$ anuales que se quedan en la Europa atlántica, un centenar de kg emprenden la ruta del Báltico al año y $150 \mathrm{~kg}$ van en dirección a las zonas mediterráneas.

Además de reforzar la monetización de Europa, el Atlántico americano logró perfeccionar las técnicas productivas de los bienes de exportación. Entre las más importantes figuran 
las técnicas de producción azucarera, iniciadas en las Antillas inglesas e imitadas rápidamente por las Antillas francesas y Brasil, en especial para la utilización de los residuos de la caña y el uso de los nuevos alambiques para la producción de melaza. También en la producción de la plata y el oro se asiste a un ulterior perfeccionamiento de la técnica de la amalgama, que se utiliza asimismo para la producción de oro. La expansión de las producciones y de las exportaciones americanas, además de integrar definitivamente a la América británica continental al tráfico internacional de tabaco y trigo, favorece la integración de Francia a las nuevas potencias atlánticas gracias a sus producciones en las Antillas. La consolidación del mundo atlántico permite destacadas innovaciones en la navegación oceánica. Recuérdese el perfeccionamiento en el primer tercio del siglo xvi del sextante, acompañado del almanaque náutico, que permite determinar la fecha corriente en relación con el ángulo entre el sol y la luna, y por último, la invención del cronómetro en 1761, capaz de calcular con exactitud la medición de la longitud, lo cual hace posible calcular con precisión la fecha de llegada de la nave. La navegación transoceánica obtuvo grandes beneficios de la técnica constructiva del clíper, inventado en la América británica, que garantiza una mayor seguridad y velocidad en las travesías.

La consolidación del mundo atlántico acentuó el interés de las metrópolis en reforzar el control sobre sus propias colonias americanas. La nueva dinastía de los borbones transfirió las reformas políticas y administrativas de España a las zonas americanas. Entre las más significativas figuran el fin progresivo del monopolio real del comercio y la apertura de los principales puertos de la Península y de América al comercio directo. Además, los territorios americanos fue- 
ron reorganizados, constituyendo el virreinato de la Nueva Granada (Colombia) y el del Río de la Plata (Argentina), y se introdujo el sistema francés de la intendencia (prefectura) en los diversos distritos de los virreyes y gobernadores. Se trató esencialmente de reducir el control territorial ejercido por las oligarquías hispanoamericanas, derogando el contrato de exacción de los impuestos internos en las colonias.

Un proceso similar sucede en Brasil, donde además de la reorganización del comercio entre los puertos portugueses y brasileños, se asiste a la unificación de las 14 capitanías en un virreinato, con sede en Río de Janeiro, y se extiende al virreinato la reorganización acontecida en la metrópoli en los sectores de la justicia y la fiscalía. La reorganización española y portuguesa tenía el objetivo de frenar la penetración de Gran Bretaña y de Francia en el Atlántico ibérico y de obtener mayores recursos de las colonias. Esta novedad modificó la tradicional lealtad de las élites iberoamericanas a las respectivas coronas, como lo demuestra el hecho de que los nobles nacidos en América comenzaron a definirse ya no más como españoles o portugueses, sino como americanos, y reivindicaron el derecho a los títulos reales para los cargos públicos previstos en los territorios americanos.

La acción realizada por la corona francesa en sus zonas atlánticas fue de menor alcance, a pesar del rápido crecimiento de éstas. La corona trató de aumentar su propio peso en las colonias, aunque sin introducir un refuerzo institucional del poder metropolitano. El resultado fue que en Santo Domingo se creó una fuerte tensión entre los colonos y la autoridad colonial, que se incrementó con la concesión de la ciudadanía a los mulatos libres en 1791, lo cual favoreció 
la insurrección de los esclavos y el nacimiento de la república en Haití en 1793.

El autogobierno de las 13 colonias de la América británica tuvo que enfrentarse a la voluntad de la corona de redefinir las relaciones con su periferia. De hecho, entre 1651 y 1659, con las nuevas leyes de navegación, trató de controlar las relaciones comerciales con las Antillas holandesas y francesas. En el último tercio del siglo Xvir y el primer tercio del siglo siguiente, el mayor éxito de la corona fue poner fin al asentamiento de colonias privadas, mientras las asambleas de colonos se oponían a la política del Parlamento inglés, empeñada en reducir la autonomía de las colonias. La única medida que se implementó con la ley de navegación de 1696, voluntad del Parlamento, fue la creación de la Cámara de Comercio que, además de controlar principalmente el comercio de la metrópoli con las colonias, imponía a las asambleas de colonos la entrega a los gobernadores, nombrados por la corona, de las rentas necesarias para la gestión administrativa de las colonias.

A partir de 1760, el Parlamento inglés trata de asumir una mayor autoridad en las relaciones con las colonias, buscando uniformar la imposición fiscal colonial con la existente en la metrópoli. El aumento de los impuestos sobre el consumo y la aplicación del sello en documentos, periódicos y opúsculos suscitaron una notable oposición de los angloamericanos.

En cambio, la presencia de las metrópolis europeas fue mínima en las zonas atlánticas africanas. Los asentamientos portugueses se dan sobre todo en las islas de Cabo Verde y Santo Tomás, Príncipe y Fernando Po, mientras que en el continente sólo en las zonas de la costa de Angola y Mozambique se da una reducida presencia portuguesa. Lo mismo sucede respecto a Francia en la zona de Senegal y respecto 
a Gran Bretaña en la zona del río Gambia. El único asentamiento auténtico es el holandés, que desarrolla la Compañía de las Indias Orientales en el cono sur de África. Ese sitio se desarrolla a partir de la edificación de una fortaleza en 1652, que más tarde se convertirá en la Ciudad del Cabo, un lugar previsto para el abastecimiento de las naves en la ruta de las Indias. A partir de 1680, la compañía holandesa autorizó a los gobernadores a organizar la inmigración de colonos hugonotes residentes en Holanda. A principios del siglo xvi, la población de la colonia, incrementada por los cruces interétnicos, logra iniciar un sistema de haciendas agrícolas capaces de alimentar a la ciudad y de abastecer de carne salada y harina a las naves. A mitad del siglo, la frontera de los boers cubre un espacio de $800 \mathrm{~km}^{2}$.

La mayor presencia de europeos en África sigue siendo la de los comerciantes franceses e ingleses que logran penetrar en el interior navegando el río Senegal y el Gambia. También ellos, como los portugueses, se adecuan a las prácticas existentes en los mercados africanos. De este modo se refuerzan las redes mercantiles entre comerciantes europeos y africanos, y estos últimos se ponen en condiciones de crear las producciones necesarias para alimentar y vestir a los esclavos que llegan a los puertos y para aprovisionar a los comerciantes europeos. No obstante, las conexiones entre europeos y africanos producirán solamente un pequeñísimo porcentaje de población africana europeizada.

\section{LAS REVOLUCIONES ATLÁNTICAS}

La diferenciación de las zonas americanas de sus metrópolis se manifiesta primero en demandas de una mayor autono- 
mía y representación política, demandas que se transforman, a partir del último tercio del siglo xvin, en revoluciones que provocan en el mundo atlántico y europeo la caída del antiguo régimen absolutista entre el último tercio del siglo XVIII y el primero del siguiente.

A partir de la década de 1950, se desarrolla en el ámbito historiográfico la idea de que el final del antiguo régimen se consuma gracias al papel desempeñado por las revoluciones atlánticas que conmocionaron tanto el mundo americano como el europeo. Las revoluciones americanas, francesa y latinoamericanas favorecen el fin del viejo orden porque se desarrollan bajo el lema de la libertad política y económica, junto con la defensa de la soberanía nacional, con miras a fundar entidades estatales republicanas y constituir los nuevos estados sobre la base de la voluntad de los ciudadanos.

Entre 1776 y 1826, en todo el mundo atlántico se desarrolla el impulso revolucionario que halla en la Ilustración el fundamento intelectual común que se expresa en las constituciones escritas. Las constituciones atlánticas tienen la característica de definir los respectivos países como repúblicas soberanas y de atribuir a los ciudadanos, portadores de derechos y de deberes, la decisión de organizar gobiernos que puedan ofrecer las garantías necesarias a la libertad de los ciudadanos, su seguridad, y la defensa de sus propiedades. Las constituciones reconocen los derechos del hombre y del ciudadano, y establecen que el estado republicano deber estar organizado sobre la base de la soberanía nacional y la colaboración entre los poderes estatales: el ejecutivo, el legislativo y el judicial.

El proceso revolucionario atlántico hunde sus raíces en los cambios acontecidos en el curso del siglo XviII, que con la 
Ilustración y la revolución comercial, modificaron la sociedad y la cultura atlánticas. Es así como se puede explicar por qué las revoluciones de la América atlántica contribuyeron a acentuar los vínculos entre los estratos políticos e intelectuales de las dos orillas del Atlántico y a hacer posible el pasaje de la Ilustración al liberalismo.

El mecanismo desencadenante de las revoluciones atlánticas es la crisis fiscal de las monarquías europeas. Las necesidades financieras de Gran Bretaña generan la oposición de los colonos a los nuevos gravámenes, dando origen al principio de que los tributos deben ser decididos por representantes electos. La crisis fiscal favorece la convocatoria de los Estados Generales en Francia. Las restricciones fiscales impuestas a las colonias iberoamericanas y francesas favorecen la insurrección política. Además, en las zonas iberoamericanas, las élites son contrarias al uso que hacen las coronas de sus recursos financieros y al incremento de los impuestos al consumo, que desencadenan insurrecciones populares. Las revoluciones atlánticas tienen en común la circunstancia de desarrollarse a partir de una guerra civil. En Estados Unidos la guerra civil estalla entre los británicos monárquicos y los independentistas. En las revoluciones francesas es la oposición entre monárquicos moderados y republicanos la que da origen a una guerra civil. También en Iberoamérica se desencadena una guerra civil propiamente dicha entre independentistas y monárquicos.

En las tres revoluciones atlánticas, la superación de los conflictos se consigue con el reconocimiento del orden constitucional. En Estados Unidos la Constitución confederal de 1777 y la federal de 1787 favorecen la conciliación entre los diversos grupos de interés. La tumultuosa evolución cons- 
titucional de la revolución francesa marca las diversas etapas de la conciliación: la Constitución de 1791 reconoce los derechos del hombre y del ciudadano, la división de poderes en una monarquía limitada y la distinción entre ciudadanos activos y pasivos; la Constitución de 1793 afirma el principio republicano y el sufragio universal; y por último, la Constitución de 1795 establece un poder ejecutivo colegiado, un legislativo bicameral y una magistratura por elección. En Iberoamérica, entre 1813 y 1883, tenemos una pluralidad de constituciones en los distintos países. Todas tienen como modelo la Constitución liberal de Cádiz de 1812, reconocen los derechos del hombre y del ciudadano, la forma republicana y la división de poderes, y se diferencian entre constituciones confederales y unitarias.

Se puede sostener por tanto que el dinamismo de las conexiones atlánticas está en la base del orden liberal europeo y americano. Además, se puede decir que las transformaciones del mundo atlántico conformaron la primera red contemporánea de relaciones internacionales entre los estados, caracterizada por el reconocimiento del derecho internacional y los tratados bilaterales.

La unidad de las revoluciones atlánticas es visible en el papel que estos países desempeñan en la afirmación del abolicionismo esclavista, que se concretará en el fin definitivo del tráfico de esclavos en Europa y las Américas.

Traducción de Isabel Vericat 


\section{REFERENCIAS}

Albertone, Manuela y Antonio de Francesco (comps.)

Rethinking the Atlantic World. Europe and America in the Age of Democratic Revolution, Basingstoke, Palgrave Macmillan, 2009.

Armitage, David y Michael J. Braddick (comps.)

The British Atlantic World, 1500-1800, Basingstoke, Palgrave Macmillan, 2002.

Armitage, David y Sanjai Subra (comps.)

The Age of Revolutions in Global Context. C. 1760-1840, Macmillan Basingstoke, Palgrave, 2010.

BAYLIN, Bernard

Atlantic History. Concepts and Contours, Cambridge, Mass., Harvard University Press, 2005.

Butel, Paul

Histoire de l'Atlantique de l'antiquité a nos jours, París, Perrin, 1997.

Canny, Nicholas y Philip Morgan (comps.)

The Oxford Handbook of the Atlantic World c. 1450-c. 1850, Oxford, Oxford University Press, 2011.

Carmagnani, Marcello

El otro Occidente. América Latina desde la invasión europea hasta la globalización, México, El Colegio de México, Fondo de Cultura Económica, Fideicomiso Historia de las Américas, 2011.

Las islas del lujo. Productos exóticos, nuevos consumos y cultura económica europea, 1650-1800, México y Madrid, El Colegio de México, Marcial Pons, 2012.

Economía y política. México y América Latina en la contemporaneidad, México, El Colegio de México, 2011. 
Eltis, David y David Richardson (comps.)

Atlas of the Transatlantic Slave Trade, New Haven, Yale University Press, 2010.

Findlay, Ronald y Kevin H. O'Rourke

Power and Plenty. Trade, War, and the World Economy in the Second Millennium, Princeton, Princeton University Press, 2007.

Goldstone, Jack

Why Europe? The Rise of the West in World History, 15001850, Boston, McGraw Hill, 2009.

Greene, Jack y Philip Morgan (comps.)

Atlantic History: A Critical Appraisal, Oxford, Oxford University Press, 2009.

Hensel, Silke et al. (comps.)

On the Concept and Representation of Constitutions in the Atlantic World, Newcastle upon Tyne, Cambridge Scholar Publishing, 2012.

KLein, Herbert S.

The Atlantic Slave Trade, Cambridge, Cambridge University Press, 1998 (ed. italiana, Roma, Carocci, 2014).

Klooster, Wim

Revolutions in the Atlantic World: A Comparative History, Nueva York, New York University Press, 2009.

Mancke, Elizabeth y Carole Shammas (comps.)

The Creation of the British Atlantic World, Baltimore, Johns Hopkins University Press, 2005.

Mariano, Marco

"Il Mondo Atlantico tra storia moderna e contemporanea: periodizzazioni, confini, parole chiave", en Ricerche di Storia Politica, 2 (2013), pp. 199-210. 
MeINIG, D.W.

The Shaping of America. A Geographical Perspective in 500 Years of History: Atlantic America, 1492-1800, New Haven, Yale University Press, 1986.

Morelli, Federica, Clément Thibaud y Geneviève Verdo (comps.)

Les Empires atlantiques des Lumières au liberalism (17631865), Rennes, Presses Universitaires de Rennes, 2009.

Mollat du Jourdin, Michel

L'Europa e il mare, Bari, Laterza, 1993.

PAlMer, R.S.

The Age of Democratic Revolution: A Political History of Europe and America, 1760-1800, Princeton, Princeton University Press, 1959.

Pieper, Renate y Peer Schmidt (comps.)

Latin America and the Atlantic World, Viena, Bohlau Verlag, 2003.

Romano, Ruggiero

Mecanismo y elementos del sistema económico americano: siglos XVI-XVIII, México, El Colegio de México, Fondo de Cultura Económica, Fideicomiso Historia de las Américas, 2004. 
